Portland State University

PDXScholar

$5-25-2018$

\title{
Managerial Accounting Strategies for Optimal Costs
}

Ivy Wong

Portland State University

Follow this and additional works at: https://pdxscholar.library.pdx.edu/honorstheses Let us know how access to this document benefits you.

\section{Recommended Citation}

Wong, Ivy, "Managerial Accounting Strategies for Optimal Costs" (2018). University Honors Theses. Paper 595.

https://doi.org/10.15760/honors.604

This Thesis is brought to you for free and open access. It has been accepted for inclusion in University Honors Theses by an authorized administrator of PDXScholar. Please contact us if we can make this document more accessible: pdxscholar@pdx.edu. 


\section{Table of Contents}

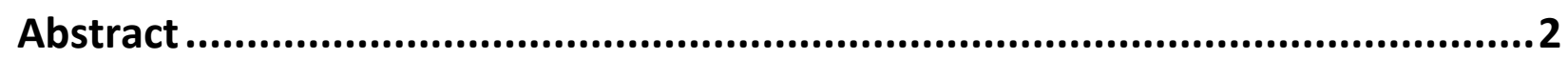

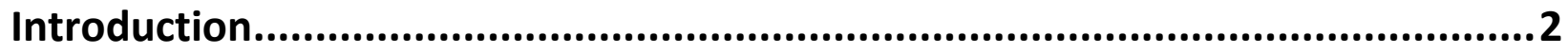

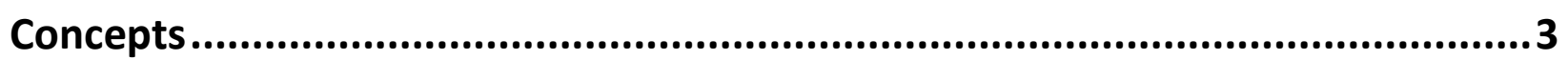

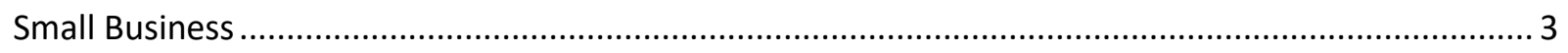

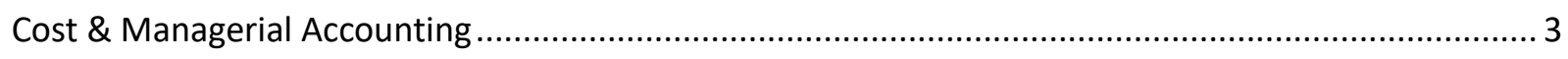

Literature Review ....................................................................................

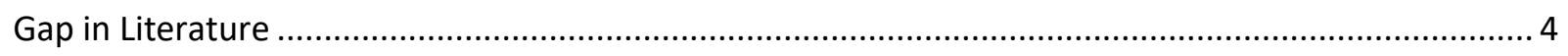

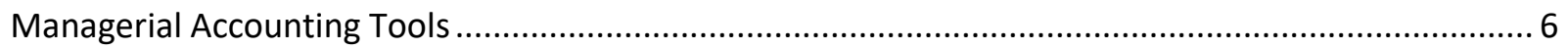

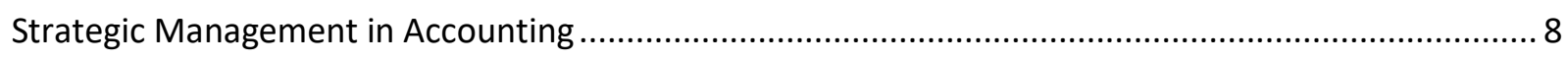

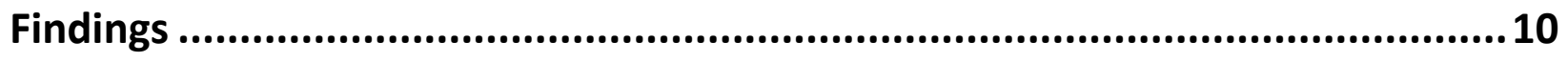

Project Recommendations ......................................................................... 11

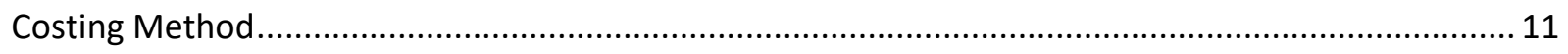

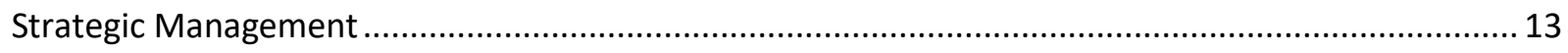

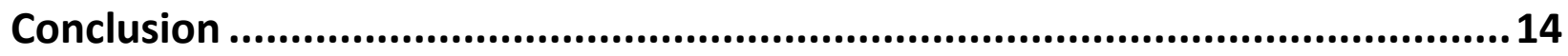

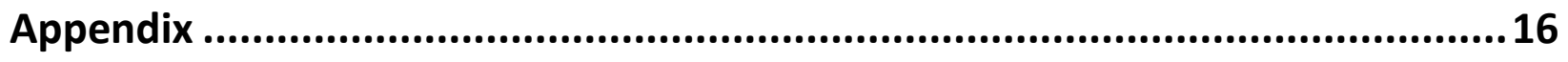

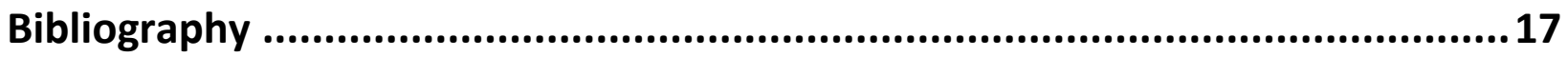




\begin{abstract}
:
During my Business Capstone class, I had the opportunity to work with a small local business. This business presented needs for managerial accounting tools that would be useful in optimizing costs and expanding their business beyond the local market. In my literature review, I focused on topics surrounding costing tools and methods and strategic management in accounting for small businesses. I found that with modifications that make costing tools more manageable for small businesses, they can play a beneficial part in a business' overall strategy. Through research and discussions with the Client, I developed recommendations focused on job costing and strategic management for small businesses. For job costing, I developed a spreadsheet based on the job costing method that would allow for book titles to be looked at separately and list out the costs associated with a print run of books. The benefits of creating this spreadsheet I found is that it gives the client a chance to look at any costs that may be incurred when printing and later selling books. As each book has its own market, the spreadsheet allows for costs to be allocated based on each book title rather than on all the books together. In strategic management, I recommend the client take a deeper look at their financial statements, particularly their balance sheets and income statement. The benefit to doing so is that it gives the client a chance to step back after a publishing season and look at their progress.
\end{abstract}

\title{
Introduction:
}

In my experience attending managerial accounting classes and taking part in discussions regarding aspects of strategy, it is easily noticed that the most common examples of costing tools and strategic management are often put in context of how large organizations, mainly corporations utilize them. After reading a thesis written on the use of costing tools in small business, I questioned how would this be useful when looking at strategy and cost optimization. Small businesses make up a large percentage of the US economy, but often there is limited research dedicated to them in accounting and in strategy. My intention for this paper is to provide further insight into the importance of managerial accounting tools for all businesses and discuss the role that strategy plays in small businesses with regards to cost optimization. 
The focus of my work with my Business Capstone Client looks at costing methods and strategical management using managerial accounting tools. I will explore the usage of costing methods such as job, product, or activity-based (ABC) costing in small businesses and the benefits and difficulties in using those tools in business strategy. Ultimately, my research will lead to recommendations of costing methods and strategical improvements that would be beneficial for the client.

The remaining portion of this introduction provides relevant insight into a few concepts. Next, I provide a literature review that discusses the uses and perceptions of managerial accounting tools in small businesses and strategy. Then I discuss findings related to the literature review and their relevance for small businesses. Finally, I introduce the Business Capstone Client I worked with and provide recommendations for the client.

\section{Concepts:}

\section{Small Business}

Typically, the employee count of a small business does not exceed 500 people. Based on industry standards, a business with 20 employees or a business with 200 people can all be called a small business. In Oregon, small businesses make up a big part of the landscape of businesses. According to the Small Business Administration, 97.6\% of businesses are considered small businesses (Small Business Administration). In 2012, the total number of firms in the state of Oregon was 339,305 (US Census Bureau). Small businesses are very attractive because they allow almost anyone with an idea the opportunity to start a business and most do not require a degree to get started. In the case of my client, because they only have around five or six employees, the business would be categorized as a small business.

\section{Cost \& Managerial Accounting}

When the word "accounting" is mentioned, most people are familiar with what is considered financial accounting. The focus of financial accounting is reporting financial information to external parties like banks, investors, government agencies, etc. based on GAAP or Generally Accepted Accounting Principles which are set by FASB, the Financial Accounting Standards Board. That information mainly affects manager decisions and actions through compensation, often based on numbers found in financial statements (Datar, Horngren, \& Rajan 
2015). Managerial and cost accounting however, slightly differs from financial accounting as it measures, analyzes, and reports financial and nonfinancial information that helps managers make decisions that fulfill the goals of the organization itself (Datar, Horngren, \& Rajan 2015). This means that instead of reporting to external parties like financial accounting does, the information gathered gets reported to internal parties like management and executives within the organization meaning it doesn't necessarily have to comply with GAAP. When thinking about managerial accounting, it is important to keep in mind two things about these practices: how will this information help managers to do their job better, and do the benefits of producing this information exceed the costs? (Datar, Horngren, \& Rajan 2015).

\section{Literature Review:}

In this literature review, I will be providing more support for my look into small businesses, managerial accounting tools, and strategy. First, I will discuss literature related to small businesses and look at the need for further research. Then I will examine the use of managerial accounting tools in small and medium enterprises and the perceptions of their usefulness in small businesses. Lastly I will look at business strategy using managerial accounting tools and the benefits and difficulties in using them.

\section{Gap in Literature}

Much of the literature I found focuses mainly on managerial accounting practices used in small and medium enterprises or SME's. As stated earlier, depending on the industry a company falls under, a company with 20 employees can be considered a small business in one industry while a business with 200 employees could also be considered a small business in another industry. Due to this broad categorization, it can be difficult to suggest managerial practices that can be applied across multiple categories of small businesses. What may work for one kind of small business may need to be reworked for it to work in another kind of small business. Often, cost-benefit analyses must be done to ensure that any tools suggested don't take up too many resources and can realistically be used in a business' daily practices. 
Looking at the research I have collected, I have found various articles that discussed managerial accounting and their uses in SME's, but there are few articles that discuss the importance for small business to have knowledge of managerial accounting. As explained by Datar, Epstein, and Yuthas (2009), certain topics such as cost management, budgeting, and risk management need to be taught to small business owners as sometimes they are not aware of what goes into their business such as how much of their product to produce that would allow them to break even or make a profit. Even if owners of "microbusinesses" as they are called in the article have access to methods of financing their business like microfinance loans, that alone doesn't guarantee success for the business. To be successful, a business and its owner must have the knowledge and skills to manage and use any financial capital they do have. It is the application and management of accounting techniques that will separates success from failure (Datar,et al. 2009).

Nandan (2010) also discusses the importance of owner-managers of SME's to understand management accounting information. The author stresses that because SME's face similar complexities as larger businesses and organizations and are more prone to failures, understanding management accounting information can be beneficial as it allows for better resource management and allocation decisions. As SME's are important within the economy and often are the "seedbed" that new, large companies grow from, the need for timely, accurate, and reliable management accounting information should be well understood (Nandan, 2010). Even if owner-managers of SME's turn to outside sources to acquire the information they need, because outside sources have their limits, possessing knowledge of management accounting techniques along with consulting the right parties to develop filters through which such techniques can become part of the knowledge base can help SME owner-managers to grow their business.

From these articles, it can be seen that knowledge and proper application of managerial accounting techniques can play a big part in whether a small business eventually succeeds or fails. While this is one of the few articles that directly connects microbusinesses with managerial accounting, that lack of connection and apparent "gap" in literature is what makes it difficult to see the purpose of managerial accounting and their uses in SME's. Many of the skills and knowledge mentioned in this article are often what is taught in basic managerial accounting classes for accounting students. However, in those classes these skills are often applied to large 
companies and corporations. Due to that, it can be difficult to find ways to translate the skills learned and apply them to SME's which function differently than large companies and corporations. Beyond the basic accounting techniques that can be easily taught, it is hard to believe that small businesses would be able to use other techniques that are available. I will discuss this further in the next section.

\section{Managerial Accounting Tools}

As explained earlier, there is some research discussing managerial accounting and their usage in SME's. For SME's, special attention is required when it comes to management accounting because of the distinct resources they have, but also distinct difficulties compared to large enterprises (Lopez \& Hiebl, 2015). Unlike larger companies that typically have a more complex operating environment like operating in multiple jurisdictions, more diverse product lines, and use mass production approaches (Armitage, Webb \& Glynn, 2016), the simpler organizational structure of SME's allow them to be more flexible and adaptable to changes (Lopez \& Hiebl, 2015). However, SME's can run into difficulties because of limited access to resources and small ability to take advantages of economies of scale, so to compete with larger enterprises, SME's must manage the scarce resources they do have using proper information and control systems (Lopez \& Hiebl, 2015). Usually in the early stages of their organizational life cycles, SME's tend to focus on "search" activities that may involve developing and testing hypotheses about customer segments, distribution channels, pricing, strategy, etc. until they reach a point in which they are more established and considered "growth firms" (Blank, 2012 as mentioned in Armitage, Webb \& Glynn, 2016). From then on, those "growth firms" then start to focus on "execution" activities that are then related to implementing strategies, developing control systems, etc. (Blank, 2012 as mentioned in Armitage, Webb \& Glynn, 2016). Therefore, management accounting can be very important to SME's as they meet general management information needs and an important corporate function that supports main business functions by providing information that is valuable for management planning and control (Lopez \& Hiebl, 2015). 
In conducting field interviews of 22 SME's, Armitage et al. (2016) found that while there were some managerial accounting techniques that saw moderate or high usage by SME's like operating budgets, balance scorecard/SPMS, variance analysis, and financial statement analysis, there were also some techniques that saw low or no usage by SME's such as flexible budgets, capital spending analysis, cost behavior analysis, activity-based (ABC) costing, etc. SME's simply often didn't use them because of how complex they were, or had a lack of resources or time to devote to the technique itself. An example that was given was that in many of the SME's interviewed, for analyses and internal reporting, Excel was often used as it was adaptable and simple to tailor and organize according to the needs of the company. If there were any techniques that the SME's interviewed thought that would help them to improve and better manage future performance, those showing interest in adopting other techniques talked about including more sophisticated forecasting systems, detailed costing systems, customer support management tools, and revenue management systems (Armitage, Webb \& Glynn, 2016).

In another study, Chiarini looked at lean production and problems that can come with deciding what kind of management accounting to utilize in SME's. In lean production, often businesses are trying to find and eliminate "waste" that can occur when producing products from raw materials to the finished product. To account for it, accounting systems need to be able to show and utilize financial savings as well as increase cash flow to be able to keep the business going. The author found that rather than using traditional accounting methods which when utilized could result in mistakes made to product cost calculations and rejections of Kaizen events, it would be better to use ABC costing or value stream accounting as they work better with different methods of production such as lean production and the accounting and calculations when utilizing either of these methods can become simpler, allows for certain changes to be more easily implemented, and possibly more accurate (Chiarini, 2012).

As the business of the Capstone client I am working with has been around a few years, it would be useful to look at management accounting going forward. Davila and Foster (2005) found positive associations between adoption of operating budgets and company growth for businesses in the early-stage. As forward-looking financial planning components like operating and cash budgets are most likely to be adopted before financial monitoring components like variance analysis, product and customer profitability, customer acquisition costs, etc. as the scale 
of the company increases, the need for management accounting increases. (Davila \& Foster, 2005). In performance management, which encompasses managerial accounting, rather than just focusing on internal and short term planning and hoping that any tools utilized for these plans translate to long term benefits, it would be important for SME's to take a strategic and long-term view approach. SME's should be proactive about changes rather than waiting for outside forces to impose change on them (Ates et al., 2013).

\section{Strategic Management in Accounting}

When looking at business strategies, there are near endless possibilities and methods that can be utilized and looked at. Strategy, in its most basic definition are a set of goal-directed actions that a firm takes to gain and sustain superior performance relative to competitors (Rothaermel, 2017). In managerial accounting and accounting in general, the role that they play can help provide information for strategic decision making and the monitoring of strategies (Bromwich, 1990). As explained in an article, depending on the strategy of the firm, systems such as control systems would be utilized differently. If a firm's strategy is more stable, then it is likely that their usage of said systems would be utilized less intensively than a firm that has a competitive strategy. A firm's strategy would also be dependent on the industry environment in which the business operates. Firms that are high performing or "Prospector" firms might be more concerned with forecast data in their control systems, setting tight budget goals and monitoring output by the company carefully therefore reducing cost control while "Defender" firms might be more concerned with bonus remuneration based on budget target achievements which causes little change in control systems (Simons, 1987).

Looking at strategies and the benefits of using managerial accounting to build and improve upon the strategy of a business, as most articles focus on larger enterprises, I will be connecting some of the interviews and studies mentioned previously with studies related to specific accounting tools utilized by businesses and their connections to specific components of business strategy. Armitage et al. (2016) found that while there are few studies that have examined the use of specific management accounting techniques such as strategic performance measurement systems (Hudson, Smart \& Bourne, 2001 as mentioned by Armitage, Webb \& 
Glynn, 2016), there has been research attention that has focused on the usage of management accounting techniques by larger firms looking at either the usage of specific tools such as ABC costing and strategic performance measurement systems or the extent to which a broad set of techniques are being used and the factors influencing their use (Abdel-Kader \& Luther et al., 2006 as mentioned by Armitage, Webb \& Glynn, 2016). In the case of SME's, though it was suggested earlier that a firm's strategy may affect how certain systems are utilized, in other documented samples, there were some SME's that had systems that weren't closely tied to their business strategy (Hudson et al, 2001 as mentioned by Armitage, Webb \& Glynn, 2016). Therefore, the concept of strategic management accounting, which is "the provision and analysis of financial information on a firm's product markets and competitors' costs and cost structures and the monitoring of the enterprise's strategies and those of its competitors in these markets over a number of periods" (Bromwich,1990) seems plausible and viable. However, as this article doesn't imply whether it would be sustainable in SME's, there are questions as to whether strategic management accounting and the theories behind it would be applicable to small businesses in general.

As cited in her thesis, "the root cause of either small business failure or poor performance is almost invariably a lack of management attention to strategic issues."(Jennings \& Beaver, 1997, cited in Andersen, Cobbold \& Lawrie, 2001, as mentioned by Beard, 2017) Issues such as the need for a clear sense of direction, understanding of the business model, and the need to focus and prioritize are basic issues of strategic management that are relevant to any business, regardless of size (Andersen et al., 2001 as mentioned by Beard, 2017). As it is common that small businesses rarely take the time to undergo a comprehensive review of their business strategy and activities (Cook \& Wolverton, 1995 as mentioned by Beard, 2017), certain tools like balanced scorecards can give SME's the opportunity to translate business strategy into actions to create a focus for the future rather than just a measure of past performance (Gumbus \& Lussier, 2006 as cited by Beard, 2017). However, as with any suggestion and later implementation of tools used in business strategy, another important aspect is to have the support needed to follow through. As owner-managers of SME's are likely because of various reasons such as a lack of funds, fear in loss of control, etc. to want to handle many aspects of their business themselves, having the right support and resources to help carry any proposed strategy forwards can be beneficial to any company seeking to grow and expand. "You have to have people on board, 
otherwise you are not going to get the support. The curse of too much complexity is the blessing of having people with you." (Simons, 1987)

\section{Findings:}

As there is an archive of literature that discusses small businesses, I will be looking at my findings and relating them to literature that discusses small and medium businesses or SME's. From articles written about SME's, it is obvious that businesses of any size can find benefits in using managerial accounting tools as part of their business strategy. With some modifications and adjustments according to the industry and size of the business, many of the more commonly used managerial accounting tools can be used by just about any kind of small business. Looking at the tools and methods discussed in the previous section by Armitage et al. (2016), Chiarini (2012), etc. budgets and costing tools seem to be the most applicable for small businesses. For most small businesses, cash or simple operating budgets seem the most relevant. As shown in their sample, budgets are often the earliest managerial accounting tool adopted and have shown a positive correlation between the adoption of these tools and company growth. (Davila \& Foster, 2005) Cash budgets and subsequently operating budgets can help small businesses in managing their limited resources, aid in the creation of schedules and optimal costs, and ensure that they are prepared should any opportunities arise that could be advantageous for the business.

With many complicated and advanced methods and costing tools out there to choose from, it has been shown in previous literature that implementing such complicated and advanced tools can only outweigh the costs if the company has the size to employ people to maintain it. For small businesses, it is best to recommend simpler methods or tools. Job costing for example is a costing system that is simple to understand and can be easily implemented (Balakrishnan et al., 2012 as cited by Beard, 2017). It doesn't require advanced technology or an excessive amount of time to maintain so it is ideal for small businesses as costs can be easily tracked using an Excel spreadsheet or other simpler methods.

Based on the literature that has been written, regardless of a business' size there is a need to understand a business's overall strategy and its strategic management (Andersen et al., 2001; Von Bergen \& Benco, 2004 as mentioned by Beard, 2017). Small businesses should take the time to define their business strategy and what tools to implement. As small businesses have 
simpler structures, it would be unnecessary to utilize accounting tools in the same manner as a larger business. If small businesses develop or adapt a set of strategic performance questions and assess these questions on a periodic basis, this allows the business to check in on their progress and reduces chances of the business becoming lost or disoriented. This can be done with something as simple as a Microsoft Word document or an Excel spreadsheet thereby reducing costs spent on complicated or expensive software. For small businesses looking to expand, being able to manage and communicate their strategic objectives to new employees or even potential investors could be the difference between a company being able to react if opportunities come or being stuck and letting the opportunities pass by.

\section{Project Recommendations:}

During spring term 2018, I had the opportunity to work with a team of fellow business students and a local small business for my Business Capstone class. For nondisclosure purposes, the business I worked with will be referred to as "Client" or "Company". The Client is a limited liability company (LLC) in the book publishing industry. The company mainly consists of the two owners who currently work part time with the business while holding down other jobs. There are also one or two interns, a commissioned salesperson, and some contractors like an accountant who handle some business responsibilities like filing taxes or marketing their books. The Client publishes books in a variety of genres and sells them through a distributor and direct sales through their website, Portland Night Market, and small local retailers. In discussions with the Client, I learned that the company had difficulties with their operating cash flows due to payment terms and seasonality. The Client is also subject to excess inventory, contractual limitations, and international holidays. This affects their ability to sell their entire catalogue of books, control their print runs, and sell their books through certain channels. The Client is considering expanding internationally, licensing their books overseas, and possibly acquiring another publisher with a strong back catalogue of books.

\section{Costing Method}

The most pressing priority for my client was to find breakeven projections to determine how many books they need to sell from their current catalogue and how many books they need in 
their catalogue to generate more revenue. I decided to look at creating a simplified job costing system for each of the books in their current catalogue. The job costing method that I am using is a special kind of job costing where the method is used to "cost" multiple units of distinct products, in this case books. As each book produced creates its own market, the job costing system spreadsheet is useful in that it separates out the costs that would be associated with each book title. I will be focusing this system on direct sales from the client. The first step would be to use a platform that is simple and easy for the client to use on a periodic basis. I chose to use Microsoft Excel as the main platform to create this system as it is relatively simple to use and accessible for the client. This simplicity and ease of use is important for the client as they are trying to build a catalogue of books beyond what they have currently. An alternative would be to use Google Sheets as since it is web based, it is also easily accessible to the client and like Microsoft Excel that anything built could be transferred between the two platforms with some formatting changes that would be accounted for due to the differences in platforms.

The spreadsheets would contain all the costs that the business incurs and is broken down by a title in the catalogue. For each separate spreadsheet, there are separate tabs that allow for different cost categories to be broken and allocated based on total direct sales revenue from the previous year and selling price per book. As some costs, such as direct material (DM) and direct labor (DL) costs are incurred by the supplier, for the DM and DL tabs I would allocate those costs based on the print run size for each book. At the top of each tab, there would be a table that states the book being printed, the number in each print run, the allocation of total DM and DL costs from the supplier, the variable and fixed costs of the printed book, the selling price of the book, and the profit margin for each book. Conditional formatting on each spreadsheet will also be applied so that the profit margin will be green if above a certain percentage, and red if below. As it is difficult to determine just how many books each print run will contain, formulas will be used in certain cells so that results can be adjusted according any changes in print run under the "Projections" tab. The Client can enter in the number of books in a print run and a projected number of books they expect to sell from that print run, and those numbers will be transferred into the direct materials tabs and produce the projected profit margins for that print run. As material costs change depending on the planned print run, the client will need to be able to easily change and account for those material changes. See Appendix for an example of a book title tab of the spreadsheet. 
The purpose of using this costing method and tool is to help the client understand their costs proportional to the books they currently have in their catalogue. This also allows them to see their profit margins per book and see what books are selling well and which ones may need to be improved upon. As this tool is mainly aimed towards their direct sales channels, this also gives the client a chance to compare their projected sales with what their actual sales turn out to be. By allocating the fixed costs as they pertain to each book title, this allows the client to see what genre of books are costing them more and if they make changes, how that can affect the remaining costs associated with the book. As it relates to optimal costs that would be beneficial for the client, it is difficult to pin down an exact number of books to produce and sell as costs can change due to other circumstances such as seasonality, global political issues, shift in resources, etc. International expansion can be costly and while licensing books can decrease some of the costs associated with each book, those costs would still need to be accounted for when looking at their sales. I hope that with this costing system it gives the client a better look at their current catalogue of books and ideas of how they should expand their catalogue without taking away the profits they are already bringing in from their current catalogue.

\section{Strategic Management}

Through the research I have done this term, I sought to look at what might be the best strategy would be the most useful for the Client. From an accounting standpoint, I found that while the Client has a lot of ideas, from looking at the financial documents and discussions with other members of my Capstone team, there were some opportunities that look to be beneficial for the Client and are suggested as possible for the Client to plan and later implement.

Although some of the strategies aren't applicable to some small businesses, for my Capstone Client looking forward towards their future, it would be important to not just look at what strategies could be implemented several years later, but also strategies that the Client could start planning and later implementing in a shorter period of time.

I believe that for the Client, the first step to reorganizing their strategy is to take a deeper look at the financial statements for the current catalogue of books. In a financial forecast the team did for the Client, I noticed that for the client to have future positive cash flow, their yearly sales would have needed to be more strategically efficient, even more efficient than well-known 
publishing companies like Scholastic. However, it was also noticeable on the financial forecast that as sales grew, costs were growing as well. For the Client, when taking a deeper look at their financial statements, their yearly sales and expenses would be metrics that warrant a closer look as their sales and expenses are closely tied together to the point that any growth in revenue or sales also equals an increase in costs. This can be done at the end of a selling period or at the end of their fiscal year to evaluate how their books are selling and whether they are on track with their path and the direction they want to go. Since the industry the Client operates in requires them to always be thinking and planning, a possible next step would be to implement strategies that would be valuable to the Client such as certain modified aspects of a balanced scorecard or other strategic performance measurement systems. The implementation will be done gradually and focused on ensuring that the Client has a chance to take advantage of opportunities available in the industry and put strategies in place that will help them with their future goals. I believe by gradually implementing certain processes or tools, reassessing their current catalogue periodically, and focusing in on niches that can help with any future expansion goals, this will give the Client a better look at the state of their business and what actions could be taken in the future should they want to explore other options as they expand.

\section{Conclusion:}

The purpose of this paper was to provide further insight into the importance of managerial accounting tools for all businesses and to discuss the role that strategy plays in small businesses with regards to optimizing costs. Through a literature review I examined current research on small businesses and perceptions from SME's regarding various managerial accounting tools as well as how strategy is used in managerial accounting. I related key findings to small businesses, found that with modifications and simplifications most managerial accounting tools can be used for any business regardless of size, and the importance of strategy in the growth of small businesses. This research assisted in my work with the Client where I was able to recommend a modified costing method and strategies that may assist the Client going forward.

Going forward, I believe that there are still many avenues of research still to be explored. Surveys and interviews with small businesses may yield new information about what tools and strategies owners have knowledge of and feel best suit their business. Without knowing what 
businesses already have in place or are willing to implement, it would be difficult to make suggestions that could be beneficial for further improvement. Small businesses make up a big part of the American economy and strategic managerial accounting tools can be a great help for small businesses looking to expand or improve their company. Tools such as balanced scorecards, break-even analyses, operating budgets, etc. are often used in businesses of all sizes to gain an insight into the expenses and costs that a business must undertake on a day to day basis. They can be applicable for forecasts on how many units of certain items need to be produced to break even with their costs, annual internal reports done within a business to see if they are earning enough revenue to break even or generate profits, inventory analyses to see the number of raw materials, work-in-progress products, and finished products they have in their inventory, and more. As another thesis author once wrote: "Managerial accounting is an incredibly important tool in ensuring businesses of all sizes are able to reach their full potential." Understanding their importance and being able to implement it into a business' strategy gives the business the ability to adapt so that should any opportunities come knocking, they are prepared. 


\section{Appendix:}

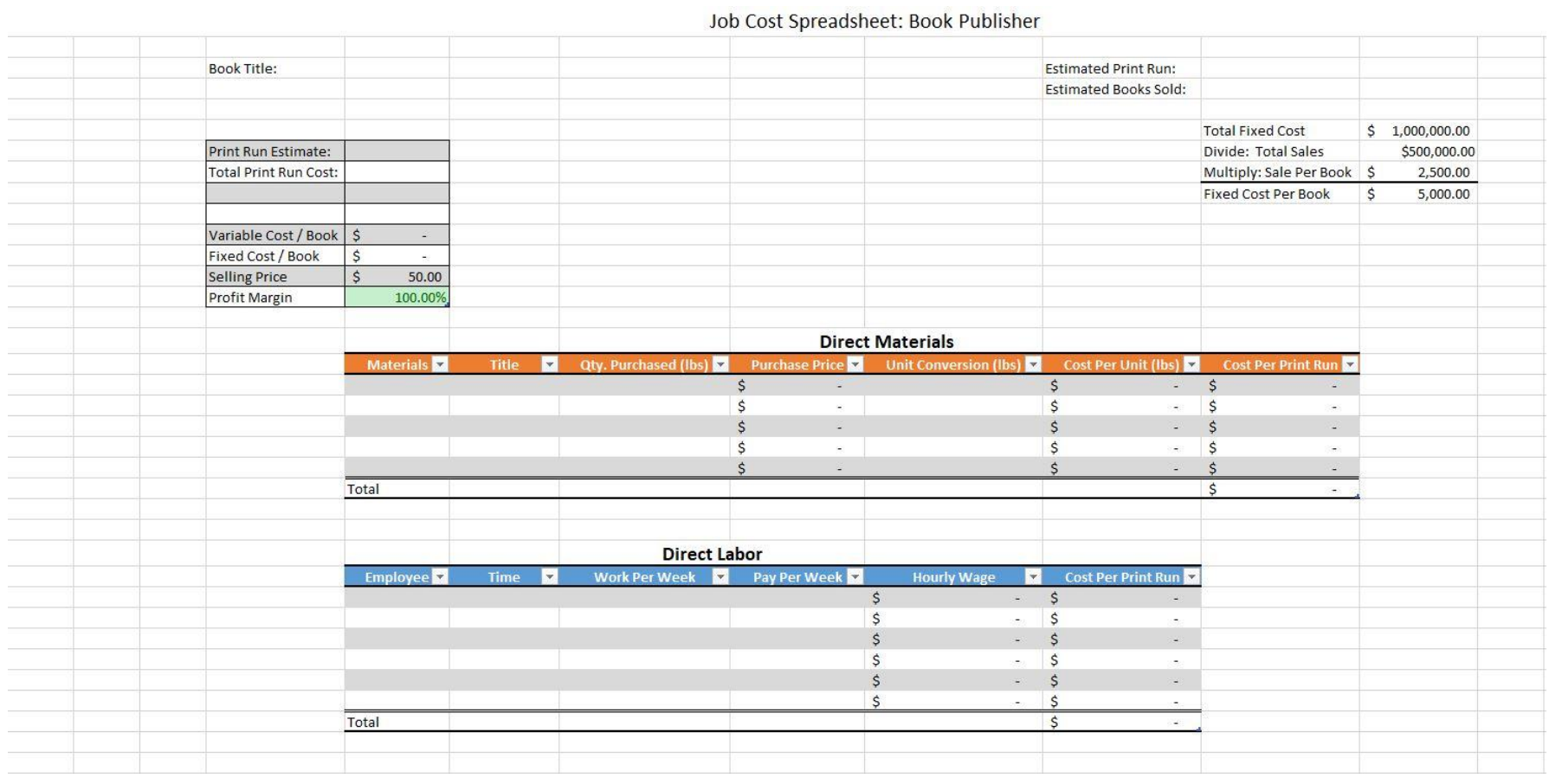

Note: Manufacturing Overhead is not shown for each title as overhead from each book title can later be combined to calculate the total overhead from the entire catalogue. 


\section{Bibliography:}

Armitage, H. M., Webb, A., \& Glynn, J. (2016). The Use of Management Accounting Techniques by Small and Medium-Sized Enterprises: A Field Study of Canadian and Australian Practice. Accounting Perspectives, 15(1), 31-69.

Ates, A., Garengo, P., Cocca, P., \& Bititci, U. (2013). The development of SME managerial practice for effective performance management. Journal of Small Business and Enterprise Development, 20(1), 28-54.

Beard, S. (2017). Modifying Managerial Accounting Tools for Microbusiness Practices. University Honors Theses. Paper 383. https://pdxscholar.library.pdx.edu/honorstheses/383

Bromwich, M. (1990). The Case for Strategic Management Accounting: The Role of Accounting Information for Strategy in Competitive Markets. Accounting, Organizations and Society, 15(12), 27-46.

Chiarini, A. (2012). Lean production: Mistakes and limitations of accounting systems inside the SME sector. Journal of Manufacturing Technology Management, 23(5), 681-700.

Datar, S. M., Epstein, M. J., \& Yuthas, K. J. (2009). Management Accounting and Control: Lessons for and from the World's Tiniest Businesses. Strategic Finance, 27-34.

Datar, S. M., Horngren, C. T., \& Rajan, M. V. (n.d.). The Manager and Management Accounting. In Cost Accounting: A Managerial Emphasis (15th ed., pp. 3-4). Pearson.

Davila, A., \& Foster, G. (2005). Management Accounting Systems Adoption Decisions: Evidence and Performance Implications from Early-Stage/Startup Companies. The Accounting Review, 80(4), 1039-1068. doi:10.2308/accr.2005.80.4.1039

López, O. L., \& Hiebl, M. R. (2015). Management Accounting in Small and Medium-Sized Enterprises: Current Knowledge and Avenues for Further Research. Journal of Management Accounting Research, 27(1), 81-119.

Nandan, R. (2010). Management Accounting Needs of SMEs and the Role of Professional Accountants: A Renewed Research Agenda. Journal of Applied Management Accounting, 8(1).

Rothaermel, F. T. (2018). What is Strategy? In Strategic Management, Third Edition (p. 4). McGraw-Hill Education. (Original work published 2017)

Simons, R. (1987). Accounting control systems and business strategy: An empirical analysis. Accounting, Organizations and Society, 12(4), 357-374.

Table of Small Business Size Standards | The U.S. Small Business Administration. (2017, October 1). Retrieved February 22, 2018, from https://www.sba.gov/contracting/getting-startedcontractor/make-sure-you-meet-sba-size-standards/table-small-business-size-standards United States Census Bureau (2015). Quick Facts United States 
2016 Small Business Profiles for the States and Territories. (n.d.). Retrieved February 23, 2018, from https://www.sba.gov/advocacy/small-business-profiles-states-and-territories-2016 